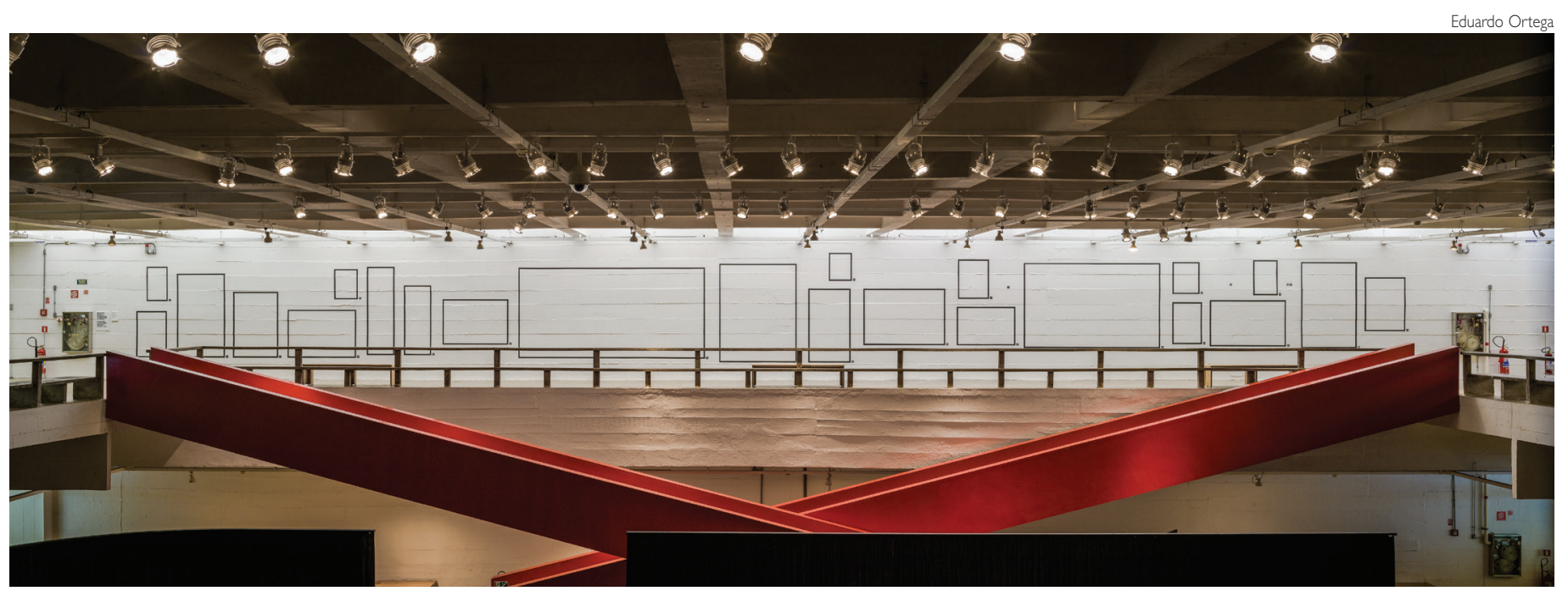

Instalação no Masp faz refletir sobre ausências, questionando onde estão as mulheres, negros e os gays nos espaços museológicos

\title{
DIVERSIDADE
}

\section{Os DESAFIOS DA MUSEOLOGIA DE GÊNERO}

Uma longa parede ocupada por molduras de diversos tamanhos, mas sem as respectivas pinturas. Essa é a instalação Elementos de beleza: um jogo de chá nunca é apenas um jogo de chá da artista plástica Carla Zaccagnini, do acervo do Museu de Arte de São Paulo (Masp). Para além de um incômodo inicial que a obra pode suscitar, a instalação traz uma mensagem forte, ela emoldura várias ausências. Afinal, o que não vemos nos museus? Que lugar ocupam as mulheres, os negros, os gays nos espaços museológicos? Ao questionar as escolhas que determinam os acervos e exposições nos museus, a museologia de gênero busca ocupar esses espaços para reverter essas ausências em afirmação de identidades femininas, LGBT ou étnico-raciais. A discussão de questōes de gênero nos projetos museológicos se insere em um movimento internacional iniciado na década de 1980 que passa a questionar a função social dos museus e que foi denominado de Nova Museologia ou Museologia Social. "É nesse campo fértil, e hoje em expansão, que se assenta a possibilidade de uma museologia de gênero, a partir de uma mirada feminista, cujas discussões inspiram um olhar crítico à forma como os museus, enquanto dispositivos de poder, acabam por perpetuar posturas sexistas e machistas", afirma Camila Wichers, museóloga e arqueóloga da Faculdade de Ciências Sociais da Universidade Federal de Goiás (UFG). A partir da perspectiva da museologia de gênero é possível considerar outras identidades, além da masculina, como eixos estruturadores dos patrimônios culturais e das coleçôes museológicas.
ESTEREótIPOS "Como arqueóloga, me incomodava o fato de que as mulheres indígenas que produziram as vasilhas cerâmicas que eu analisava ficassem invisibilizadas nas narrativas construídas pela arqueologia. A menção recorrente ao 'homem pré-histórico' também não me agradava. Depois, já em diálogo com a museologia social, observei que as representações nos museus reforçavam as narrativas arqueológicas androcêntricas", conta Camila. Segundo ela, nos museus históricos, por exemplo, os homens são frequentemente retratados nos postos de controle político. No campo da arqueologia, as narrativas tendem a reproduzir no passado (as vezes muito recuado) os estereótipos de gênero do presente, perpetuando sexismos e assimetrias. "Dessa forma, machos/homens são fortes, agressivos e dominantes. Fêmeas/mulheres são apresentadas como fracas, passivas e dependentes. Cabe à museologia desestabilizar visões sobre o passado e presente, produzindo contra-narrativas 
sobre o gênero e cartografias de resistência nos espaços culturais e museológicos e também fora deles", afirma.

Novas narrativas museológicas permitem encontrar mulheres como chefes de família, garimpeiras, parteiras, benzedeiras, cozinheiras, quitandeiras, lavadeiras, professoras, entre outros ofícios que desafiam o estereótipo do feminino confinado no universo doméstico e a conduta passiva e submissa. Essa foi a proposta da exposição Mulheres no sertão goiano: violências, educação, ofícios e direitos, em cartaz ao longo de julho deste ano no Museu de Antropologia da UFV. A mostra foi organizada por alunos do curso de museologia da universidade. "Nosso objetivo era provocar uma reflexão sobre o lugar da mulher no sertão de Goiás, construindo uma reflexão profunda sobre cenários de opressão e de libertação feminina na sociedade goiana", afirma Tony Boita, professor do curso de museologia da UFV, responsável pela exposição. Outro tema abordado nessa exposição foi o ofício geracional. Mantido por mulheres urbanas, indígenas e campesinas, foram e são importantes instrumentos que fortalecem a cultura e economia de muitos municípios, grupos e comunidades, mas que frequentemente são invisíveis para o poder público e na história do trabalho. As bonecas Karajá, por exemplo, confeccionadas por ceramistas Karajá dos estados de Goiás, Tocantins e Pará, foram registradas como patrimônio imaterial, em 2012, nos livros de registro de saberes e expressōes do Instituto do Patrimônio Histórico e Artísti- co Nacional (Iphan). A produção de tecidos de modo artesanal, realizado por fiandeiras no interior do sertão goiano, compreendem saberes que fortalecem laços e garantem a sustentabilidade e a autonomia da mulher de Goiás. De acordo com Boita, ao ocuparem os espaços museais, essas práticas dão visibilidade às mulheres por trás delas. "O fato de Goiânia ser a quinta capital mais violenta para as mulheres no Brasil aponta a urgente necessidade de se mostrar a realidade das mulheres nesse território", diz.

MEMÓRIA LGBT Movimentos sociais podem ser molas propulsoras de mudanças na realidade dos museus na medida em que se dê voz a seus atores. "Não falo a partir do lugar da mulher indígena ou negra. Sou uma profissional de museus, posso e devo dialogar com os movimentos sociais, mas não devo ser protagonista de ações museológicas acerca dessas pessoas", comenta a pesquisadora da UFG. Isso significa que a comunidade deve estar envolvida na preservação de suas memórias e nos projetos para sua manutenção.

Se reconhecer nos museus ainda é um desafio para a comunidade LGBT. "É como se não existíssemos", lamenta o museólogo da UFG, Alex de Oliveira Fernandes. "Onde está a minha comunidade LGBT (lésbicas, gays, travestis, transexuais, transgêneros) dentro dos museus? Cadê a língua pajubá, a vestimenta das drag queens? Cadê o homem goiano gay, a feminista lésbica?", questiona.

Buscando consolidar um espaço de memória LGBT em Goiânia, Olivei-
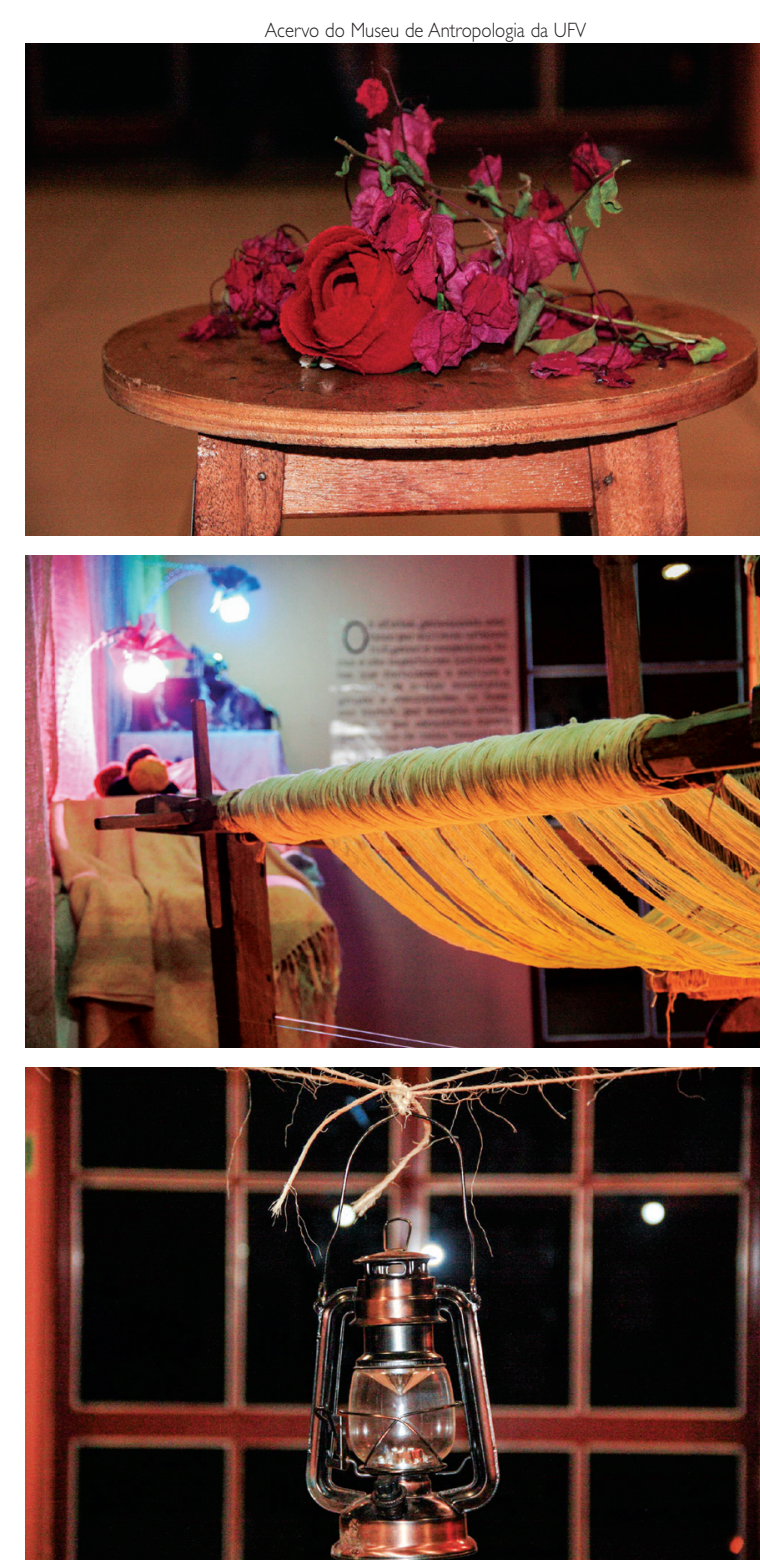

Museologia de gênero ajuda a desafiar estereótipos sobre o feminino

ra idealizou um museu de percurso, traçando os caminhos já percorridos pelo público LGBT, de forma que se possa identificar e valorizar esse patrimônio. São lugares espalhados pelo centro da cidade onde essas pessoas se sentem acolhidas e protegidas, transformando-se, assim, em espaços de afirmação de identidade. $\mathrm{O}$ processo de mapeamento foi feito por meio de 
aplicação de questionários, para caracterizar a relação dos frequentadores com os locais identificados, e de documentação fotográfica. Depois foram desenvolvidos um mapa, identificando os pontos de cultura LGBT, catálogos informativos e cartazes de identificação. Segundo Oliveira, mais do que um extenso conjunto de espaços físicos, o trabalho de mapeamento mostrou um importante patrimônio imaterial, carregado de memórias do universo LGBT.

$\mathrm{O}$ principal objetivo do museu de percurso LGBT é solidificar os laços de identificação entre lésbicas, gays, bissexuais, travestis, transexuais e transgêneros por meio de um circuito significativo para essa comunidade. "A cultura LGBT continua marginalizada e os homofóbicos fazem dessa invisibilidade uma arma. A valorização da nossa memória é um meio de confrontar a homofobia e diminuir o preconceito", acredita Oliveira.

Para Camila, o museu do percurso é um espaço conceitual e afetivo da comunidade LGBT. "Entretanto, há que se pontuar que esse trabalho se debruçou sobre espaços de homens gays. Ou seja, há toda uma discussão sobre a representatividade de outros segmentos dessa comunidade", pondera. "O museu acontece quando os membros da comunidade ou pessoas solidárias ao movimento estão juntos, dialogando, percorrendo os lugares de memória da comunidade", conclui. Esse é o meio para dar sentido aos museus. Todos devem se reconhecer neles, sob pena de restarem apenas molduras vazias.

Patrícia Mariuzzo

\section{ENTREVISTA}

\section{A INTERNET E OS MUSEUS IMAGINÁRIOS}

Entre 1935 e 1947, ao analisar as consequências da intersecção entre fotografia, técnicas de impressão e as viagens internacionais, o escritor francês André Malraux apontou para a eliminação dos enquadramentos e dos limites físicos que o museu tradicional impunha como lugar primordial para sua divulgação. Nascia aí o conceito de museu imaginário que, segundo Malraux, tem como precursor os livros de arte capazes, já no final do século XIX, de disseminar imagens em uma escala nunca vista até então. É a partir do conceito de museu imaginário que o escritor, fotógrafo e curador Pedro Karp Vasquez escreve "O caderno dos lamentos e das recriminações", ficção que relata os dramas de uma jovem apaixonada. No texto, publicado na Revista Studium (v. 37, 2016), Vasquez cria e expõe uma mostra particular com 14 fotografias coletadas na internet. A ideia é mostrar que, como previu Malraux, todos nós somos, ou podemos ser, curadores de nossos próprios museus.

Vasquez é autor de 26 livros, sendo que alguns se tornaram obras de referência como Dom Pedro II e a fotografia no Brasil (1985); Fotógrafos alemães no Brasil do século XIX (2000) e O Brasil na fotografia oitocentista(2003). É formado em

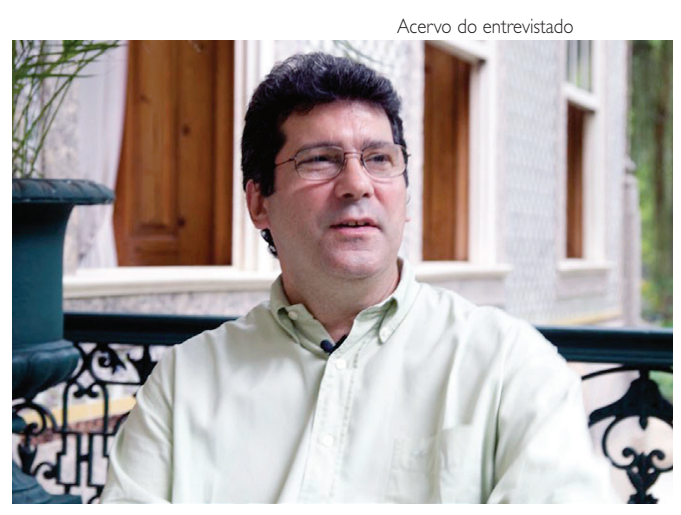

0 fotógrafo Pedro Karp Vasquez fala sobre o potencial da internet como repositório de memórias individuais

cinema pela Université de la Sorbonne e mestre em ciência da arte pela Universidade Federal Fluminense (UFF). Foi responsável pela criação do Instituto Nacional da Fotografia, da Funarte, assim como do Departamento de Fotografia, Vídeo \& Novas Tecnologias, do Museu de Arte Moderna do Rio de Janeiro. Atualmente é editor na Editora Rocco.

Nesta entrevista para a revista $C i$ ência e Cultura, Vasquez mostra como a internet se tornou fonte para se colecionar imagens e, ao mesmo tempo, um veículo de divulgação, possibilitando a cada indivíduo divulgar seu museu imaginário particular. Um exemplo é a página “Theories of the deep understanding of things" onde uma pequena equipe de anônimos seleciona obras de arte e fotografias e publica em álbuns. As novas formas de divulgação colocam em cheque as fronteiras do museu tradicional e deixam a pergunta: estamos preparados para romper as amarras do que pode ou não pode acontecer em um museu? Parece que sim. Confira a íntegra da entrevista com o fotógrafo. 